\title{
ANÁLISE DA VARIABILIDADE DA PRECIPITAÇÃO PLUVIOMÉTRICA COMO SUBSÍDIO PARA O PLANEJAMENTO AGRÍCOLA EM CAICÓ/RN
}

\author{
LUCENA, Joselma Araújo - joselma.geografia@gmail.com \\ PPGG/UFPB - Univ Fed da Paraíba \\ SOUZA, Bartolomeu Israel - bartoisrael@yahoo.com.br \\ DGEOC/UFPB - Univ Fed da Paraíba \\ MOURA, Marcelo de Oliveira - geommoura@yahoo.com.br \\ DGEOC/UFPB - Univ Fed da Paraíba \\ LIMA, Joab de Oliveira - joab@de.ufpb.br \\ DE/UFPB - Univ Fed da Paraíba
}

\begin{abstract}
RESUMO. Elementos climáticos em regiões tropicais, principalmente a pluviosidade, se mostram como insumos essenciais para a produtividade agrícola. Nessa perspectiva, esse trabalho tem por objetivo analisar a variabilidade da série temporal de chuvas como subsídio para o planejamento agrícola no município de Caicó/RN. A investigação apoiou-se na abordagem dinâmica do clima, tendo como procedimento metodológico a análise rítmica. A partir da análise dos dados, pôde ser verificada a complexidade da variação anual, sazonal e a tendência de previsão linear das chuvas na área estudada e os possíveis impactos à agricultura.
\end{abstract}

Palavras chaves: Variabilidade; Precipitação Pluviométrica; Ritmo Climático; Caicó/RN.

RAINFALL VARIABILITY ANALYSIS AS SUPPORT FOR AGRICULTURAL PLANNING IN CAICÓ/RN

ABSTRACT. Climatic elements in tropical regions, especially rainfall, appear as essential inputs for agricultural productivity. From this perspective, this work aims at analyzing the variability of rainfall temporal series as a support for agricultural planning in the town of Caico/RN. The research rested on the climate dynamic approach, having as methodological orientation the rhythmic analysis. From the data analysis, it was possible to verify the complexity of annual and seasonal variation and the linear forecasting trend of rainfall in the area studied and the possible impacts to agriculture.

Key words: Variability; Rainfall; Climate Rhythm; Caicó/RN.

\section{INTRODUÇÃo}

A precipitação pluviométrica é reconhecida como uma variável climatológica importante na região semiárida do Brasil, devido principalmente a irregularidade na sua distribuição temporal e espacial, sendo reconhecida como um dos fatores limitantes ao maior desenvolvimento e a estabilização da produção agrícola (MORAES, 2005).

O clima e as condições atmosféricas podem influenciar a produção e a produtividade agrícola, a qual é fortemente dependente das condições climáticas, uma vez que os organismos vegetais expostos às condições hídrico-energéticas necessárias ao desenvolvimento de seus ciclos, desde o plantio perpassando ao florescimento, frutificação e colheita, permitem um maior rendimento agrícola, (BALDO et al., 2001).

No caso do Brasil, essa dependência das condições pluviais é particularmente sentida na Região Nordeste, em sua porção semiárida. Esse pedaço do território nordestino é formado por um conjunto de espaços que se caracterizam pelo balanço hídrico negativo, resultantes das precipitações médias anuais inferiores a $800 \mathrm{~mm}$, insolação média de 2.800h/ano, temperaturas médias anuais que variam de $23^{\circ} \mathrm{C}$ a $27^{\circ} \mathrm{C}$, evaporação de $2.000 \mathrm{~mm} / \mathrm{ano}$ e umidade relativa do ar média em torno de $50 \%$ (BRITO et al., 2007).

De acordo com Antonino (2000), a água no semiárido nordestino é um dos fatores limitantes mais importantes à obtenção de elevadas produtividades agrícolas, principalmente por causa da extrema variabilidade das condições climáticas, fazendo com que em alguns anos o suprimento de água às plantas seja suficiente para seu crescimento e desenvolvimento, enquanto em outros anos a falta da chuva pode levar a perda total da colheita.

Nessa mesma perspectiva, Bergamaschi e Matzenauer (2009), enfatizam que o clima é o principal fator responsável pelas oscilações e frustrações das safras agrícolas no Brasil. Em se tratando da região Nordeste do Brasil, principalmente as secas prolongadas têm grande responsabilidade na variabilidade da produção agrícola. Por exemplo, a cultura do milho, também analisada nessa pesquisa, é sensível ao déficit hídrico e uma das culturas mais afetadas pela variabilidade do regime pluviométrico. A produção desse cereal pode ser 
drasticamente afetada por estiagens curtas, quando coincidentes com o período crítico ${ }^{1}$ da cultura. Por outro lado, no início do ciclo, enquanto o ponto de crescimento dessa cultura achase abaixo do nível do solo, é sensível à inundação e tende a morrer por falta de oxigênio se o solo permanecer encharcado por período prolongado (BERGAMASCHI; MATZENAUER, 2009). Com relação ao feijão, outra das culturas analisada neste trabalho, esta é uma leguminosa que se destaca em vários continentes, sendo uma importante fonte de proteína, fósforo, ferro, vitamina B1 e fibra para o ser humano. No Brasil, predomina o feijoeiro comum (Phaseolus vulgaris $L$.), que é cultivado em quase todo território nacional. Em sua germinação, valores de temperatura em torno de $28^{\circ} \mathrm{C}$ são considerados ótimos. É sabido que o rendimento do feijoeiro é afetado pela condição hídrica do solo, sendo que a deficiência hídrica pode reduzir a produtividade em diferentes proporções, de acordo com as diferentes fases do ciclo da cultura. Por outro lado, o feijoeiro é uma planta relativamente sensível ao excesso de água, sendo que o desenvolvimento vegetativo e reprodutivo são bastante prejudicados nessa condição (HEINEMANN et al., 2009).

$A b^{\prime}$ Sáber (2003) destaca que, o fator que mais dificulta a sobrevivência dos sertanejos no semiárido brasileiro é a variabilidade climática que atinge essas terras. Nesse caso, como afirmam Nunes e Lombardo (1995), embora a variabilidade seja uma componente conhecida da dinâmica climática, seu impacto, mesmo dentro de limites esperados, pode ter reflexos significativos nas mais diversas atividades humanas.

Essa característica natural é reforçada por Kayano e Andreoli (2009: 213), para quem "(...) o Nordeste brasileiro apresenta acentuada variabilidade interanual, particularmente na precipitação, com alguns anos extremamente secos e outros extremamente chuvosos". Para a prática da agricultura de sequeiro, muito comum nessa região, seria muito importante o conhecimento, não apenas da quantidade do total de chuva, mas também a sua gênese, variabilidade e tendência de ocorrência para fins de planejamento social e econômico.

Entendemos que o desenvolvimento econômico é um fator importante para a sociedade, em que também as condições naturais apresentam forte influência. Neste sentido, a análise climática fornece subsídios importantes, tanto no que diz respeito ao conhecimento da realidade dos fenômenos meteorológicos, quanto ao da organização das atividades econômicas, permitindo a integração de diversas modalidades que possibilitem aperfeiçoar os modelos de gestão ambiental (SOUZA, 2006).

Sobre essa questão, Ayoade (2006) enfatiza que, apesar dos recentes avanços tecnológicos e científicos, o clima ainda é uma variável muito importante para a produção agrícola. Embasados nessa perspectiva, foi investigada nesta pesquisa a variabilidade temporal da precipitação pluviométrica como subsídio para o planejamento agrícola no município de Caicó/RN, destacando a influência pluviométrica na produção de feijão e milho, cultivos tradicionais e de elevada importância para a subsistência da população que habita essa parte do Brasil.

\section{MATERIAL E MÉTODOS}

Caicó insere-se no semiárido potiguar, na Microrregião do Seridó Ocidental (Figura 01), situado a aproximadamente $280 \mathrm{~km}$ de distância de Natal, capital do estado. Possui uma área de $1.229 \mathrm{~km}^{2}$, comportando uma população de 62.709 habitantes (IBGE, 2010). Do ponto de vista do quadro físico dominante, essa região é caracterizada pela escassez e instabilidade das chuvas, elevadas temperaturas, baixa umidade e uma paisagem marcada pela vegetação de caatinga.

O tipo climático do município classifica-se como Tropical Equatorial (2d - com 9 a 11 meses seco), de acordo com a classificação climática de Mendonça e Danni-Oliveira (2007), caracterizado por um clima muito quente e semiárido, tendo como estação chuvosa o verão, se estendendo para o outono. A irregularidade pluviométrica é característica marcante de sua climatologia, além de apresentar níveis de insolação muito altos, elevado índice de evaporação e ventos fracos, em média.

As culturas de subsistência, milho e feijão, que são tratadas na pesquisa, são cultivadas em várzeas, no período de janeiro a abril, com semeaduras após as primeiras chuvas, apresentando um ciclo completo de aproximadamente 90 dias, embora muitas vezes a safra

\footnotetext{
${ }^{1}$ Período crítico da cultura do milho está caracterizado com duração em torno de 12 a 15 dias, justificando-se pela grande sensibilidade do milho aos estresses durante a polinização, fecundação e desenvolvimento inicial dos grãos.
} 
seja perdida quando as plântulas morrem por falta de água, devido a irregularidades das chuvas e à ausência de água armazenada no perfil do solo.

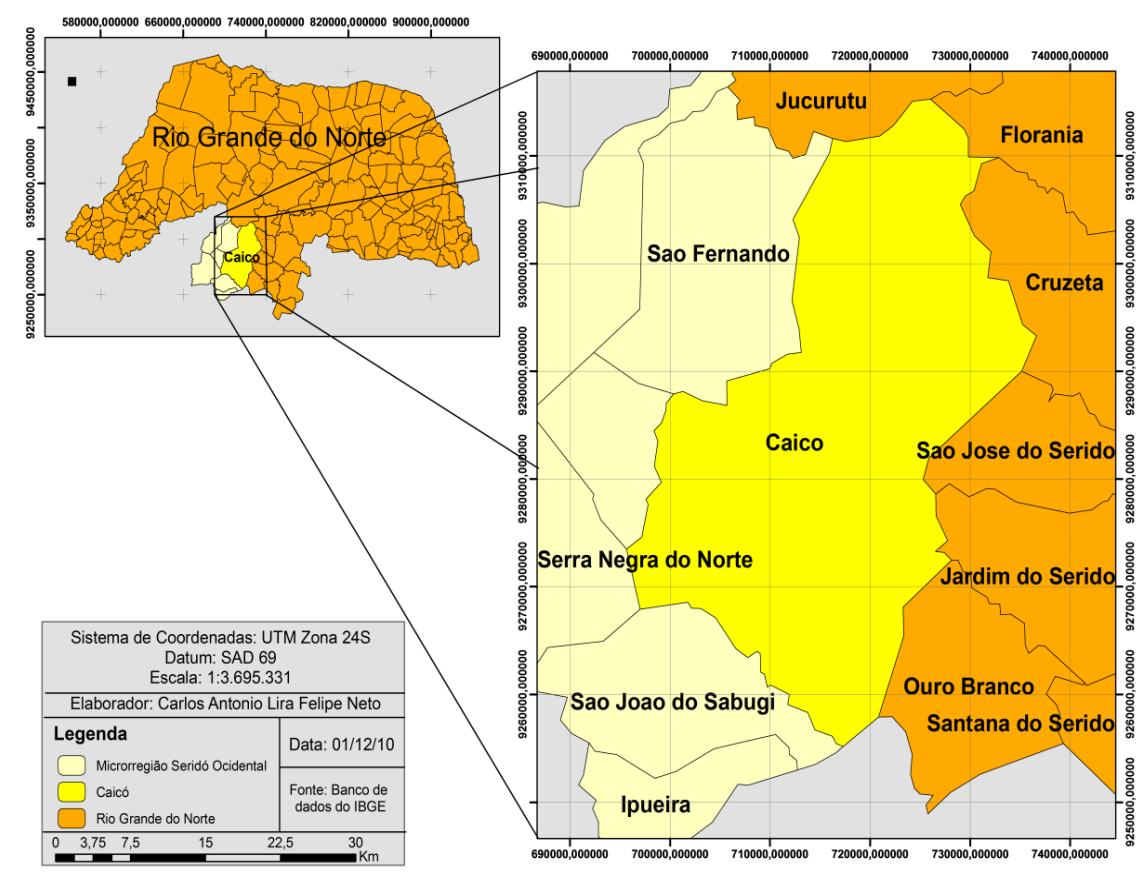

Figura 01 - Localização geográfica do município de Caicó/RN. Fonte: Adaptado de Almeida et al. (2010)

Neste trabalho adotou-se a abordagem dinâmica do clima proposta por Max Sorre (1951) em que o clima é a série de estados atmosféricos em um dado lugar em sua sucessão habitual, ajustada à análise rítmica desenvolvida por Monteiro (1971), em que a representação das variações diárias dos elementos climáticos vem associada à circulação atmosférica regional, possibilitando a explicação das mesmas.

Analisando o tempo e o clima numa perspectiva dinâmica, buscando a explicação para o ritmo climático, Monteiro (1971) afirma que:

[...] o ritmo climático só poderá ser compreendido através da representação concomitante dos elementos fundamentais do clima em unidades de tempo cronológico pelo menos diárias, compatíveis com a representação da circulação atmosférica regional, geradora dos estados atmosféricos que se sucedem e constituem o fundamento do ritmo (MONTEIRO, 1971, p. 09).

Só a análise rítmica detalhada ao nível de "tempo", revelando a gênese dos fenômenos climáticos pela interação dos elementos e fatores, dentro de uma realidade regional, é capaz de oferecer parâmetros válidos à consideração dos diferentes e variados problemas geográficos desta região (MONTEIRO, 1971, p. 12).

$\mathrm{Na}$ análise rítmica as expressões quantitativas dos elementos climáticos estão indissoluvelmente ligados à gênese ou qualidade dos mesmos e os parâmetros resultantes desta análise devem ser considerados levando em conta a posição no espaço geográfico em que se define (MONTEIRO, 1971, p. 13).

Para realização do estudo proposto, utilizou-se a série temporal de precipitação pluviométrica da Estação Climatológica do Seridó em Caicó/RN, pertencente ao Campus Universitário da UFRN/CERES, no período de 15 anos (1996 a 2010), tendo em vista ser essa série disponível com dados diários. Também foram utilizados dados da Pesquisa Agrícola Municipal realizada pelo Instituto Brasileiro de Geografia e Estatística - IBGE. Após a coleta e tabulação dos dados com a utilização da planilha eletrônica Microsoft Excel 2007, as séries temporais receberam os seguintes tratamentos estatísticos: cálculo de média, valores mínimo e máximo, desvio padrão, coeficiente de variação e tendência de previsão linear.

O desvio-padrão e o coeficiente de variação são índices que mostram a variabilidade dos dados analisados. Analisou-se também o comportamento pluvial anual e sazonal (verão, outono, inverno e primavera). A partir destes cálculos, foi construída a síntese do comportamento pluviométrico temporal de Caicó, no período de 1996-2010, estabelecendo cinco classes para 
qualificar as chuvas (seco, tendente a seco, habitual, chuvoso e tendente a chuvoso), cujas análises foram realizadas com o objetivo de selecionar os três anos-padrão (seco, habitual e chuvoso), representativos da pesquisa, através da qual se utilizou o parâmetro sugerido por Sant' Anna Neto (1990):

- ANO CHUVOSO - ano com pluviosidade elevada (excepcionalmente chuvoso), ou seja, com índices superiores a $25 \%$ da média normal.

- ANO TENDENTE A CHUVOSO - ano com pluviosidade ligeiramente elevada, próxima à média normal, com desvio entre $+12,5 \%$ e $25 \%$.

- ANO HABITUAL - ano com pluviosidade normal ou habitual, cujo total pluvial situa-se dentro dos desvios médios padrão, variando de $-12,5 \%$ a $12,5 \%$ dos índices habituais.

- ANO TENDENTE A SECO - ano com pluviosidade ligeiramente reduzida, próxima à média normal, com desvios entre $-25 \%$ e $-12,5 \%$.

- ANO SECO - ano com pluviosidade reduzida (excepcionalmente seco), ou seja, com índices inferiores a $-25 \%$ da média normal.

Sant' Anna Neto (1990) estudou a dinâmica climática e a gênese das chuvas na zona costeira paulista traçando um eixo Cananéia-Ubatuba. A investigação foi realizada com a seleção dos anos-padrão de 1981 (habitual), 1983 (chuvoso) e 1985 (seco). Nos resultados, o autor encontrou índices elevados de participação dos sistemas frontais nos períodos sazonais e concluiu que a gênese pluvial da área de pesquisa estava associada à atividade frontal.

$\mathrm{Na}$ distribuição pluviométrica mensal, com a finalidade de avaliar as variações e extrair um padrão do seu comportamento, para conhecimento do ritmo climático local, levaram-se em consideração os valores mensais distribuídos em frequência de classe em intervalos de $20 \mathrm{~mm}$, parâmetro proposto por Souza (1998); foi calculado o comportamento médio da precipitação, mês a mês, que foi denominado de médias mensais; por fim, foram calculados os índices mensais que revelam a porcentagem média de chuva a cada mês do ano.

O intervalo de classe de $20 \mathrm{~mm}$ se adequa a proposta deste trabalho devido à maioria dos anos apresentarem seus índices pluviométricos mensais nessa faixa, notadamente de julho a dezembro. Para encontrar a média mensal, inicialmente foi fixado cada um dos meses do ano e calculado o comportamento médio da precipitação mensal dentro do período estudado. Por exemplo, para o mês de janeiro a média mensal é:

$\bar{x}_{1}=\frac{240,9+54,8+\cdots+31,6+107,9}{15}=89,8$

e para o mês de dezembro:

$\bar{x}_{12}=\frac{5,0+49,2 \ldots+50,5+39,8}{15}=20,7$

no qual 15 é o número de anos analisados.

Este procedimento foi repetido para todos os meses do ano.

Os índices mensais, $\mathrm{S}_{1}, \mathrm{~S}_{2}, \ldots, \mathrm{S}_{12}$, são resultantes da divisão das médias mensais sobre o total anual médio de precipitação, ou seja, $\mathrm{S}_{1}=\bar{X}_{1} / \bar{T}$.

Onde: $\bar{X}_{1}$ é a média para cada mês da série dos anos estudados.

O total $\bar{T}$ é dado pela média da precipitação anual no período analisado. Assim,

$\bar{T}=\left(\frac{T_{1}+T_{2}+\cdots+T_{15}}{15}\right)=\left(\frac{9247,2}{15}\right)$ 
Onde $\mathrm{T}_{\mathrm{i}}$ : precipitação total do i-ésimo ano, $\mathrm{i}=1,2, \ldots, 15$.

Finalmente, na análise da produtividade agrícola (culturas temporárias de feijão, milho), os anos que apresentarem desvios do rendimento (positivos ou negativos) foram comparados com os anos-padrão (seco, habitual e chuvoso), da série histórica de chuva.

\section{RESULTADOS E DISCUSSÃO}

\section{Variabilidade da Precipitação Pluviométrica}

Nessa análise é possível observar a variabilidade anual do período estudado, apresentando consideráveis oscilações. Observa-se que os totais anuais apresentaram uma forte variabilidade de um ano para outro, não existindo uma distribuição sazonal homogênea. Na tabela 01 , temos a síntese do comportamento pluviométrico temporal de Caicó no período de 1996-2010, enquanto na figura 02 temos a Variabilidade Anual e Tendência de Previsão Linear.

Tabela 01

\begin{tabular}{|c|c|c|c|c|c|c|c|c|c|c|c|c|c|c|c|}
\hline \multirow{2}{*}{ ANO } & \multicolumn{3}{|c|}{ VERÃO } & \multicolumn{3}{|c|}{ OUTONO } & \multicolumn{3}{|c|}{ INVERNO } & \multicolumn{3}{|c|}{ PRIMAVERA } & \multicolumn{3}{|l|}{ ANUAL } \\
\hline & Total & \multicolumn{2}{|c|}{ DESVIO $^{2}$} & \multicolumn{3}{|c|}{ DESVIO } & Total & \multicolumn{2}{|c|}{ DESVIO } & \multicolumn{3}{|c|}{ DESVIO } & Total & \multicolumn{2}{|c|}{ DESVIO } \\
\hline 1996 & 469,5 & 147,5 & 45,8 & 360,5 & 119,4 & 49,5 & 29,0 & 7,9 & 37,2 & 23,0 & $-9,2$ & $-28,6$ & 882,0 & 265,5 & 43,1 \\
\hline 1998 & 155,3 & $-166,7$ & $-51,8$ & 4,7 & $-236,4$ & $-98,1$ & 29,1 & 8,0 & 37,7 & 0,0 & $-32,2$ & $-100,0$ & 189,1 & $-427,4$ & $-69,3$ \\
\hline 1999 & 126,6 & $-195,4$ & $-60,7$ & 131,7 & $-109,4$ & $-45,4$ & 5,0 & $-16,1$ & $-76,3$ & 98,1 & 65,9 & 204,5 & 361,4 & $-255,1$ & $-41,4$ \\
\hline 2000 & 388,9 & 66,9 & 20,8 & 216,1 & $-25,0$ & $-10,4$ & 109,0 & 87,9 & 415,6 & 23,9 & $-8,3$ & $-25,8$ & 737,9 & 121,4 & 19,7 \\
\hline 2003 & 244,9 & $-77,1$ & $-23,9$ & 144,2 & $-96,9$ & $-40,2$ & 15,8 & $-5,3$ & $-25,3$ & 0,3 & $-31,9$ & $-99,1$ & 405,2 & $-211,3$ & $-34,3$ \\
\hline 2004 & 603,3 & 281,3 & 87,4 & 165,3 & $-75,8$ & $-31,4$ & 17,6 & $-3,5$ & $-16,7$ & 1,3 & $-30,9$ & $-96,0$ & 787,5 & 171,0 & 27,7 \\
\hline 2005 & 299,6 & $-22,4$ & $-7,0$ & 142,0 & $-99,1$ & $-41,1$ & 3,9 & $-17,2$ & $-81,6$ & 50,0 & 17,8 & 55,2 & 495,5 & $-121,0$ & $-19,6$ \\
\hline 2006 & 293,2 & $-28,8$ & $-8,9$ & 428,4 & 187,3 & 77,7 & 5,7 & $-15,4$ & $-73,0$ & 0,5 & $-31,7$ & $-98,4$ & 727,8 & 111,3 & 18,1 \\
\hline 2007 & 299,1 & $-22,9$ & $-7,1$ & 314,8 & 73,7 & 30,6 & 3,5 & $-17,6$ & $-83,4$ & 16,0 & $-16,2$ & $-50,3$ & 633,4 & 16,9 & 2,7 \\
\hline 2008 & 486,6 & 164,6 & 51,1 & 406,3 & 165,2 & 68,5 & 10,7 & $-10,4$ & $-49,4$ & 0,0 & $-32,2$ & $-100,0$ & 903,6 & 287,1 & 46,6 \\
\hline CV & 42,6 & & & 59,3 & & & 128,5 & & & 123,5 & & & 39,6 & & \\
\hline MAX & 603,3 & & & 531,5 & & & 109,0 & & & 133,0 & & & 1054,9 & & \\
\hline MIN & 126,6 & & & 4,7 & & & 1,8 & & & 0,0 & & & 189,1 & & \\
\hline
\end{tabular}

Fonte: Estação Climatológica do Seridó - UFRN/CERES. Organização: Joselma Araújo de Lucena

\footnotetext{
${ }^{2}$ Desvio: Discrepância em relação à média.
} 


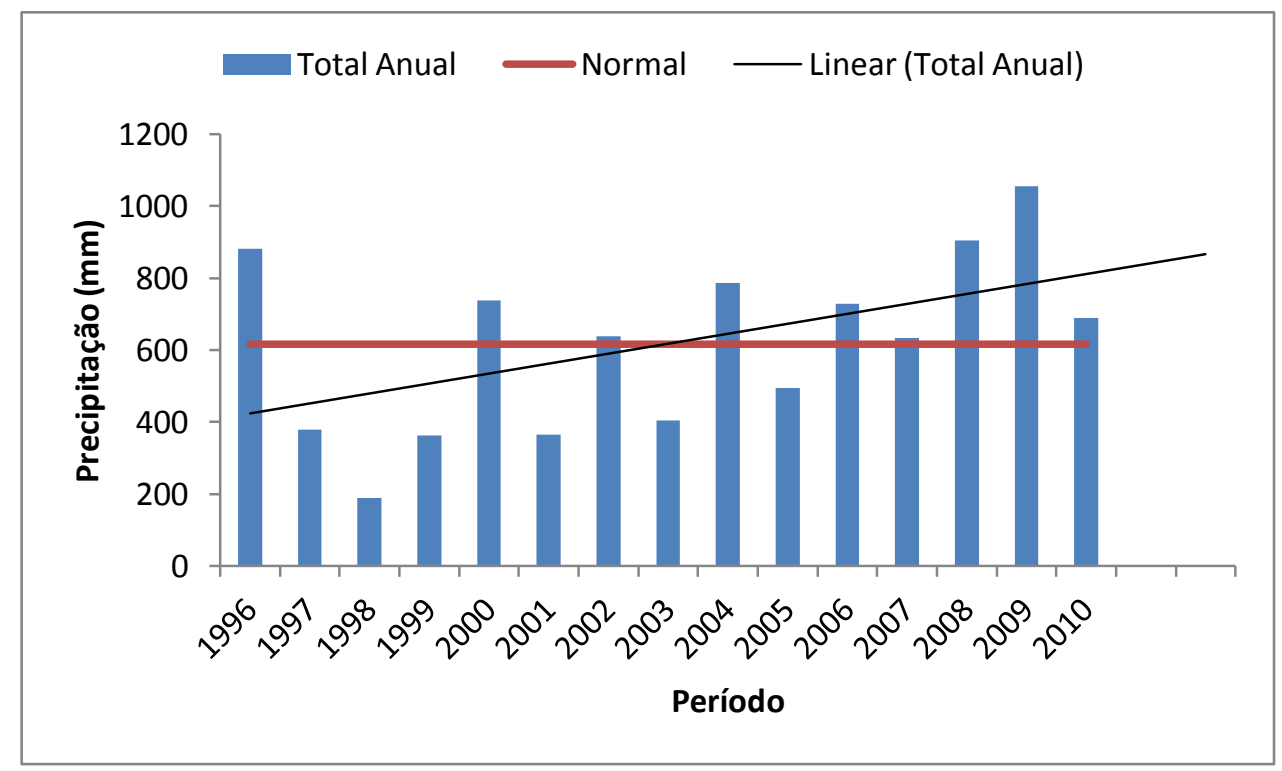

Figura 02 - Gráfico da Distribuição Pluviométrica Anual de Caicó/RN. Fonte: Estação Climatológica do Seridó - UFRN/CERES. Org: Joselma Araújo de Lucena

Nesta análise inicial, podemos verificar a complexidade da variação anual das chuvas em Caicó e a tendência de previsão linear, apontando aumento dos totais anuais.

\section{Variabilidade Sazonal}

A análise da distribuição das chuvas, considerando a sazonalidade, demonstrou que no outono, inverno e primavera o período seco é maior que os demais:

- VERÃO - reconhecida como a estação mais chuvosa do ano, com um total de 4.830,20 $\mathrm{mm}$, apresenta $26,67 \%$ dos verões chuvosos, $13,33 \%$ tendente a chuvoso, $20,00 \%$ habituais, $13,33 \%$ tendente a seco e $26,67 \%$ secos.

- OUTONO - 33,33\% chuvoso, $6,67 \%$ tendente a chuvoso, $13,33 \%$ habitual, $0 \%$ tendente a seco e $46,67 \%$ seco.

- INVERNO - considerada a estação mais seca do ano, com um total de $317,10 \mathrm{~mm}$, apresentou-se em $26,67 \%$ chuvoso, $6,67 \%$ tendente a chuvoso, $0 \%$ habitual, $6,67 \%$ tendente a seco e $60,00 \%$ seco.

- PRIMAVERA - 33,33\% chuvosa, $0 \%$ tendente a chuvosa, $0 \%$ habitual, $0 \%$ tendente a seca e $66,67 \%$ seca.

A distribuição sazonal da precipitação pluviométrica da série histórica está representada na figura (03), mostrando que as chuvas concentraram-se $52 \%$ no verão, $39 \%$ no outono, $5 \%$ no inverno e $4 \%$ na primavera. 


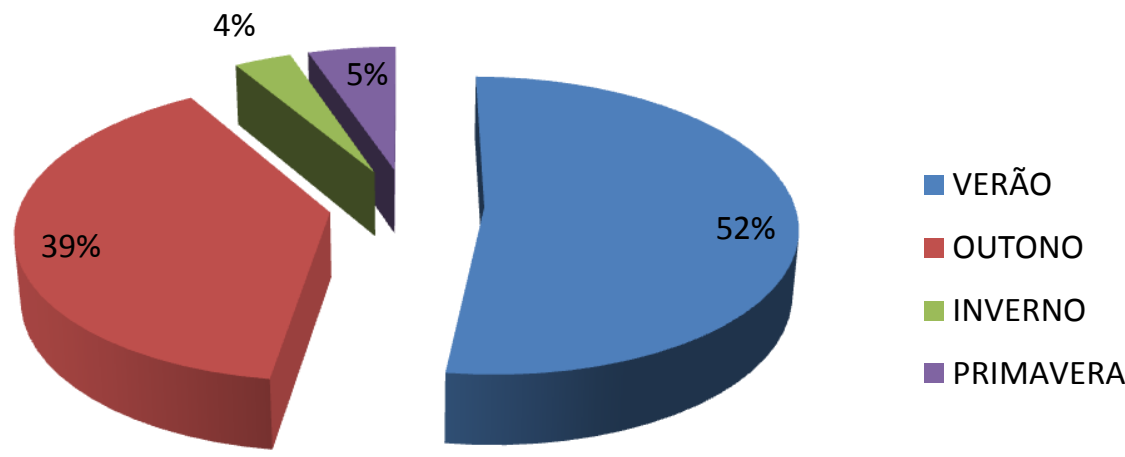

Figura 03 - Gráfico da Distribuição Sazonal das Chuvas da Série Histórica. Fonte: Estação Climatológica do Seridó - UFRN/CERES. Org: Joselma Araújo de Lucena

A figura (04) mostra a síntese da variabilidade temporal do fenômeno pluvial em Caicó: dos 15 anos analisados, 26,67\% apresentaram pluviosidade elevada (chuvoso), 13,33\% pluviosidade ligeiramente elevada (tendente a chuvoso), 20\% demonstraram padrões habituais, 6,67\% apresentaram pluviosidade ligeiramente reduzida (tendente a seco) e 33,33\% caracterizaramse com pluviosidade reduzida (seco).

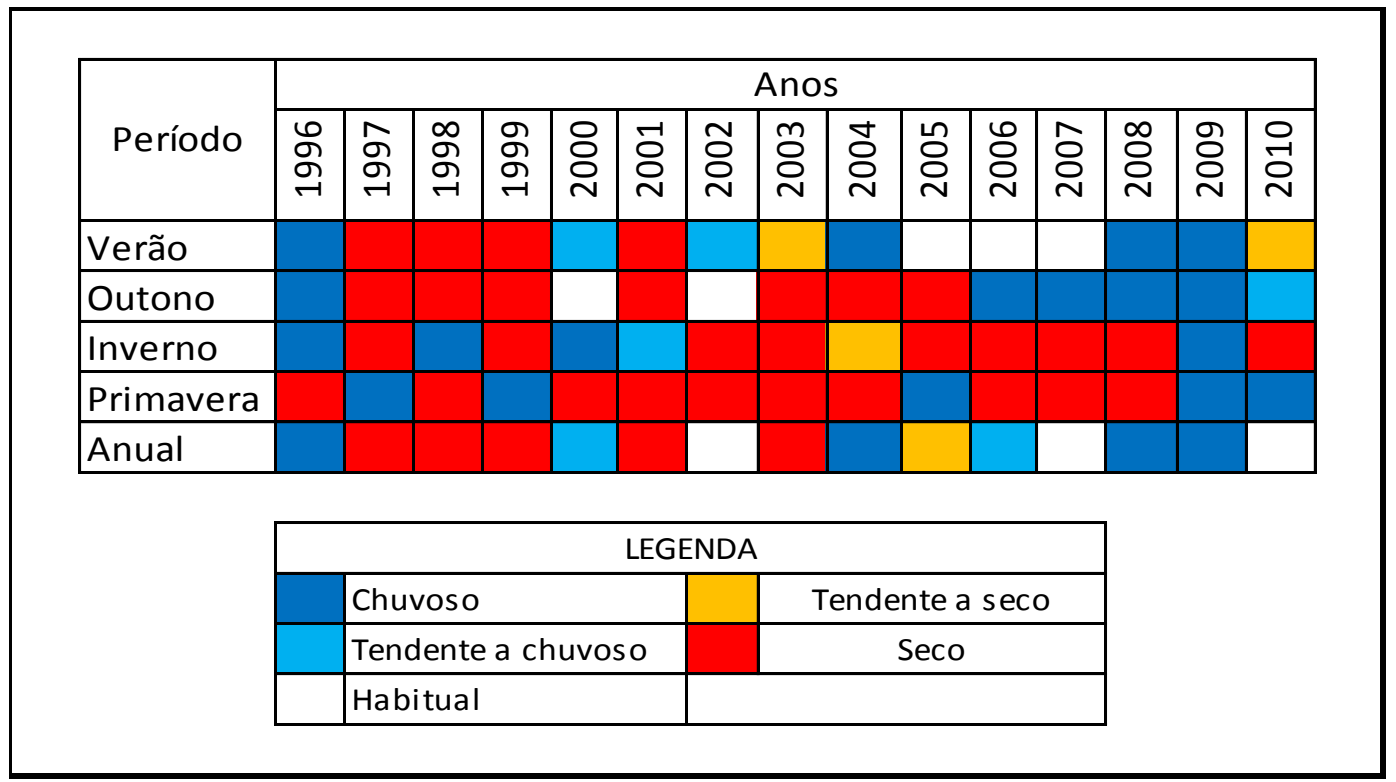

Figura 04 - Quadro Síntese da Variação Temporal das chuvas em Caicó/RN (1996-2010). Fonte:

Estação Climatológica do Seridó - UFRN/CERES.Org: Joselma Araújo de Lucena

A partir da construção da síntese da variação temporal das chuvas em Caicó, por meio das cinco classes climáticas estabelecidas, foi possível selecionar os anos-padrão de 1998 (seco), 2007 (habitual) e 2009 (chuvoso), representativos da pesquisa, de acordo com a proposta de 
Sant' Anna Neto (1990), em que se consideraram os indicadores quantitativos dos índices pluviométricos anuais e sazonais.

\section{Variabilidade Pluviométrica Mensal}

Para dar continuidade ao estudo do ritmo pluviométrico de Caicó/RN, analisou-se o comportamento da variação mensal dessa série, adotando o procedimento proposto por Souza (1998). Tal como foi dito anteriormente, estabeleceu-se o intervalo de classe de $20 \mathrm{~mm}$.

A análise da pluviometria da série temporal da estação climatológica de Caicó/RN demonstrou que a pluviosidade é maior no início do ano e desaparece entre os meses de agosto a novembro. Demonstrou ainda que a totalidade dos índices pluviométricos mensais se encontra nas primeiras faixas de 0-20 diminuindo na faixa de 20-40 e 40-60 mm para quase desaparecer nos intervalos seguintes.

Os índices pluviométricos mensais de Caicó ficaram em torno de $20 \mathrm{~mm}$ e concentrou-se nos meses de janeiro a maio, sendo março e abril os meses mais chuvosos, como pode ser observado na tabela 02 .

Tabela 02

Distribuição Pluviométrica Mensal de Caicó/RN (1996-2010) em Classes de 20 mm CLASSE JAN FEV MAR ABR MAI JUN JUL AGO SET OUT NOV DEZ

\begin{tabular}{lllllllllllll}
\hline $\mathbf{0 - 2 0}$ & 4 & 3 & 0 & 1 & 2 & 7 & 13 & 13 & 15 & 13 & 15 & 9 \\
\hline $\mathbf{2 0 - 4 0}$ & 2 & 2 & 2 & 1 & 4 & 4 & 2 & 1 & 0 & 1 & 0 & 2 \\
\hline $\mathbf{4 0 - 6 0}$ & 1 & 2 & 1 & 1 & 2 & 3 & 0 & 0 & 0 & 0 & 0 & 3 \\
\hline $\mathbf{6 0 - 8 0}$ & 2 & 2 & 0 & 2 & 2 & 1 & 0 & 1 & 0 & 0 & 0 & 1 \\
\hline $\mathbf{8 0 - 1 0 0}$ & 0 & 2 & 1 & 2 & 3 & 0 & 0 & 0 & 0 & 1 & 0 & 0 \\
\hline $\mathbf{1 0 0 - 1 2 0}$ & 2 & 0 & 1 & 0 & 0 & 0 & 0 & 0 & 0 & 0 & 0 & 0 \\
\hline $\mathbf{1 2 0 - 1 4 0}$ & 1 & 0 & 2 & 0 & 1 & 0 & 0 & 0 & 0 & 0 & 0 & 0 \\
\hline $\mathbf{1 6 0 - 1 6 0}$ & 0 & 0 & 4 & 1 & 0 & 0 & 0 & 0 & 0 & 0 & 0 & 0 \\
\hline $\mathbf{1 8 0 - 2 0 0}$ & 0 & 0 & 0 & 2 & 1 & 0 & 0 & 0 & 0 & 0 & 0 & 0 \\
\hline $\mathbf{2 0 0 - 2 2 0}$ & 0 & 2 & 1 & 0 & 0 & 0 & 0 & 0 & 0 & 0 & 0 & 0 \\
\hline $\mathbf{2 2 0 - 2 4 0}$ & 1 & 0 & 0 & 0 & 0 & 0 & 0 & 0 & 0 & 0 & 0 & 0 \\
\hline $\mathbf{2 4 0 - 2 6 0}$ & 1 & 0 & 0 & 1 & 0 & 0 & 0 & 0 & 0 & 0 & 0 & 0 \\
\hline $\mathbf{2 6 0 - 2 8 0}$ & 0 & 0 & 1 & 3 & 0 & 0 & 0 & 0 & 0 & 0 & 0 & 0 \\
\hline $\mathbf{2 8 0 - 3 0 0}$ & 0 & 0 & 0 & 0 & 0 & 0 & 0 & 0 & 0 & 0 & 0 & 0 \\
\hline $\mathbf{3 0 0 - 3 2 0}$ & 0 & 0 & 0 & 0 & 0 & 0 & 0 & 0 & 0 & 0 & 0 & 0 \\
\hline $\mathbf{3 2 0 - 3 4 0}$ & 0 & 0 & 1 & 1 & 0 & 0 & 0 & 0 & 0 & 0 & 0 & 0 \\
\hline $\mathbf{3 4 0 - 3 6 0}$ & 1 & 0 & 0 & 0 & 0 & 0 & 0 & 0 & 0 & 0 & 0 & 0
\end{tabular}

Fonte: Estação Climatológica do Seridó - Caicó/RN. Org: Joselma Araújo de Lucena 
Em relação às médias mensais, essas estão representadas na tabela 03.

Tabela 03

Totais e Médias Mensais de Chuva $(\mathrm{mm})$ da Série Histórica

\begin{tabular}{|c|c|c|c|c|c|c|c|c|c|c|c|c|}
\hline ANO/MES & JAN & FEV & MAR & ABR & MAIO & JUN & JUL & AGO & SET & OUT & NOV & DEZ \\
\hline 1996 & 241 & 90 & 138 & 256 & 86 & 19 & 21 & 7 & 1 & 2 & 16 & 5 \\
\hline 1997 & 55 & 9 & 147 & 65 & 44 & 0 & 4 & 4 & 0 & 0 & 3 & 49 \\
\hline 1998 & 103 & 18 & 34 & 4 & 0 & 1 & 14 & 15 & 0 & 0 & 0 & 0 \\
\hline 1999 & 41 & 50 & 36 & 31 & 95 & 6 & 4 & 0 & 1 & 29 & 10 & 60 \\
\hline 2000 & 74 & 185 & 130 & 177 & 2 & 38 & 38 & 67 & 4 & 0 & 1 & 23 \\
\hline 2001 & 5 & 9 & 148 & 91 & 35 & 31 & 12 & 13 & 0 & 7 & 0 & 15 \\
\hline 2002 & 219 & 29 & 155 & 151 & 67 & 11 & 2 & 0 & 0 & 1 & 4 & 0 \\
\hline 2003 & 29 & 68 & 147 & 98 & 31 & 16 & 11 & 5 & 0 & 0 & 0 & 0 \\
\hline 2004 & 342 & 219 & 42 & 68 & 28 & 70 & 15 & 2 & 0 & 0 & 0 & 1 \\
\hline 2005 & 10 & 29 & 261 & 44 & 71 & 27 & 1 & 3 & 0 & 0 & 0 & 50 \\
\hline 2006 & 0 & 89 & 204 & 262 & 122 & 45 & 4 & 2 & 0 & 1 & 0 & 0 \\
\hline 2007 & 19 & 181 & 99 & 267 & 38 & 10 & 3 & 0 & 1 & 0 & 0 & 16 \\
\hline 2008 & 70 & 79 & 339 & 270 & 95 & 42 & 10 & 1 & 0 & 0 & 0 & 0 \\
\hline 2009 & 32 & 205 & 185 & 323 & 169 & 40 & 20 & 25 & 0 & 8 & 0 & 51 \\
\hline 2010 & 108 & 51 & 109 & 175 & 46 & 56 & 4 & 0 & 6 & 93 & 0 & 40 \\
\hline Média & 90 & 87 & 145 & 152 & 62 & 27 & 11 & 9 & 1 & 9 & 2 & 21 \\
\hline
\end{tabular}

Fonte: Estação Climatológica do Seridó - Caicó/RN. Org: Joselma Araújo de Lucena

A porcentagem média mensal da precipitação, relativa a cada um dos meses do ano estão representadas na tabela (04).

De acordo com as tabelas 03 e 04, foi verificado que o período mais chuvoso engloba os meses de janeiro a abril, enquanto o trimestre mais seco do ano é representado pelos meses de setembro-novembro. 
Tabela 04

\begin{tabular}{lc}
\multicolumn{2}{c}{ Porcentagem Média Mensal da Precipitação (\%) } \\
\hline Janeiro & 14,57 \\
\hline Fevereiro & 14,18 \\
\hline Março & 23,49 \\
\hline Abril & 24,64 \\
\hline Maio & 10,03 \\
\hline Junho & 4,44 \\
\hline Julho & 1,74 \\
\hline Agosto & 1,54 \\
\hline Setembro & 0,15 \\
\hline Outubro & 1,51 \\
\hline Novembro & 0,35 \\
\hline Dezembro & 3,36 \\
\hline
\end{tabular}

Fonte: Estação Climatológica do Seridó - Caicó/RN. Org: Joselma Araújo de Lucena

\section{Seleção e análise dos anos-padrão}

Com a finalidade de avaliar a variabilidade temporal da precipitação para a escolha dos anospadrão representativos da pesquisa, consideraram-se os indicadores quantitativos dos índices pluviométricos anuais e sazonais.

- Ano padrão seco - os anos mais caracterizados como de pluviosidade reduzida foram os anos 1997, 1998, 1999, 2001, 2003. Porém, o ano 1998 apresenta o menor índice de chuva da série e de acordo com distribuição sazonal apresenta como período seco verão, outono e primavera.

- Ano padrão habitual - os anos que apresentaram uma distribuição anual das chuvas mais próximo das médias foram 2002, 2007 e 2010. Todavia, o ano 2007 apresenta o índice pluviométrico mais próximo da média da série e sazonalmente apresenta verão habitual, outono chuvoso, inverno e primavera habitual.

- Ano padrão chuvoso - no segmento temporal 1996-2010 quatro anos apresentaram pluviosidade mais elevada: 1996, 2004, 2008, 2009. Porém, analisando a distribuição sazonal das chuvas, verificou-se que no ano 2009, o período chuvoso estendeu-se do outono a primavera, com o verão habitual, e com o maior índice de precipitação da série.

\section{Variabilidade Anual dos anos-padrão}

A tabela 05 mostra que a pluviosidade na área de estudo em 2007 (ano habitual) apresentou índice anual de $633,4 \mathrm{~mm}$. No ano de 1998 (ano seco) com o total anual de $189,1 \mathrm{~mm}$, choveu $29,85 \%$ do habitual. O ano de 2009 (chuvoso) apresentou índice pluviométrico de 1054,9 mm, chovendo $166,55 \%$ do habitual. 


\section{Tabela 05}

Média Climatológica e Total de Chuva $(\mathrm{mm})$ para os Anos-padrão

$\begin{array}{ll}\text { Estação } & \text { Média } \\ \text { Climatológica } & \text { Climatológica } \\ & 1996-2010\end{array}$

Anos

1996-2010

\section{Ano Seco Ano Habitual Ano Chuvoso (1998) (2007) (2009)}

$\begin{array}{lllll}\text { Caicó } & 616,48 \mathrm{~mm} & 189,1 \mathrm{~mm} & 633,4 \mathrm{~mm} & 1054,9 \mathrm{~mm}\end{array}$

Fonte: Estação Climatológica do Seridó - UFRN/CERES. Org: Joselma Araújo de Lucena

\section{Variabilidade Sazonal dos anos-padrão}

Para a caracterização de cada estação do ano, adotou-se o "ano civil", em que temos.

- VERÃO: janeiro - fevereiro - março.

- OUTONO: abril - maio - junho.

- INVERNO: julho - agosto - setembro.

- PRIMAVERA: outubro - novembro - dezembro.

Os índices pluviométricos apresentaram-se mais expressivos no verão e inverno no ano 1998 (ano seco), no verão e outono nos anos 2009 (ano chuvoso) e 2007 (ano habitual), conforme a tabela 06:

Tabela 06

Distribuição Pluviométrica ( $\mathrm{mm}$ ) Sazonal dos Anos-Padrão

\begin{tabular}{lllll}
\hline Ano/Estação & Verão $(\mathbf{m m})$ & Outono $\mathbf{( m m})$ & Inverno $\mathbf{( m m )}$ & $\begin{array}{l}\text { Primavera } \\
(\mathbf{m m})\end{array}$ \\
\hline $\mathbf{1 9 9 8}$ & 155,30 & 4,70 & 29,10 & 0,00 \\
$\mathbf{( s e c o )}$ & & & & 16,00 \\
\hline $\mathbf{2 0 0 7}$ (habitual) & 299,10 & 314,80 & 3,50 & 58,10 \\
\hline $\mathbf{2 0 0 9}$ (chuvoso) & 421,30 & 531,50 & 44,00 & 74,10 \\
\hline Total & 875,70 & 851,00 & 76,60 &
\end{tabular}

Fonte: Estação Climatológica do Seridó - UFRN/CERES. Org: Joselma Araújo de Lucena

\section{Variabilidade Mensal dos anos-padrão}

Os maiores índices de chuva do ano de 1998 (ano seco) ocorreram no mês de janeiro, nos anos 2009 (ano chuvoso) e 2007 (ano habitual) ocorreram em abril. A distribuição mensal das chuvas nos três anos-padrão da pesquisa, conforme a figura 05, apresentou-se concentrada nos meses de janeiro a maio. 


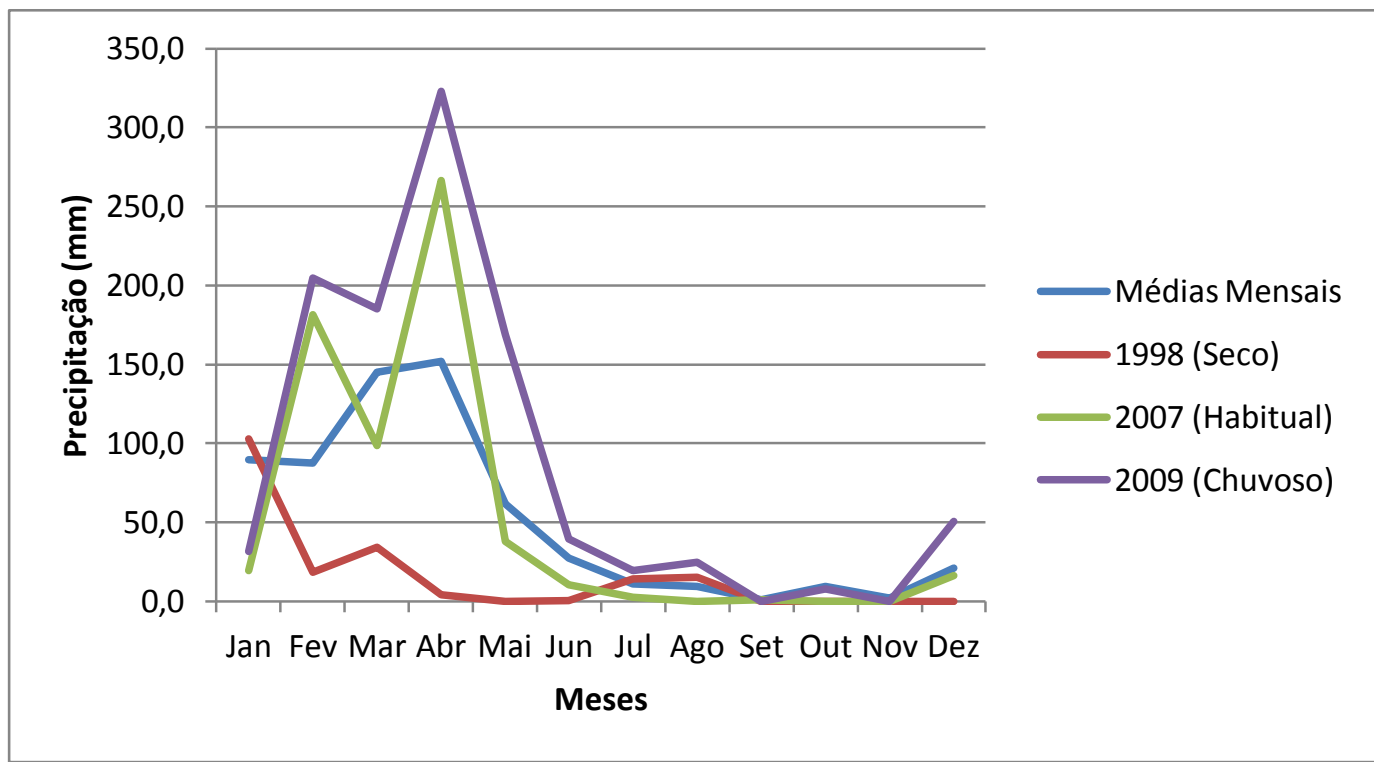

Figura 05 - Médias Mensais e Anos-Padrão. Fonte: Estação Climatológica do Seridó - UFRN/CERES. Org: Joselma Araújo de Lucena

\section{Comportamento da Produtividade Agrícola}

Na Tabela 07, é possível observar o comportamento da produtividade do feijão e do milho, principais produtos agrícolas no município de Caicó/RN para a subsistência de grande parte da população.

Nesta análise inicial, observou-se a variabilidade dos dados estudados e os desvios dos totais anuais em relação à média. Na produção de feijão, verificou-se um desvio padrão de 91,30 e o coeficiente de variação de 103,75\%. Dos 15 anos analisados, apenas 6 apresentaram desvios positivos em relação a média e 9 apresentaram desvios negativos. Na produção de milho, constatou-se um desvio padrão 112,36 e o coeficiente de variação de 135,04\%, aproximadamente $32 \%$ acima do coeficiente de variação da produção de feijão. Na análise dos 15 anos, apenas 4 apresentaram desvios positivos em relação a média e 11 tiveram desvios negativos. Ambos apresentaram coeficiente de variação muito alto, estando acima de $100 \%$.

De acordo com a análise da produção do feijão, os anos em que apresentaram maiores desvios negativos em relação à média foram $1999(-100,00 \%), 2001(-93,18 \%)$, considerados anos secos, e $2009(-92,05 \%)$, considerado ano chuvoso. Já os anos em que apresentaram maiores desvios positivos em relação à média foram 1996 (159,09\%), considerado ano chuvoso, 2000 $(104,55 \%)$, considerado ano tendente a chuvoso, e 2002 (235,23\%), com o maior percentual, considerado ano habitual.

$\mathrm{Na}$ análise da produção do milho, os anos que apresentaram desvios negativos foram 1999 ($100,00 \%), 2001(-100,00 \%)$, considerados secos, $2004(-90,38 \%)$ e $2009(-90,38 \%)$, considerados chuvosos. Já os anos que apresentaram desvios positivos em relação à média foram $1996(225,72 \%)$, ano chuvoso, $2000(188,46 \%)$, ano tendente a chuvoso, e 2002 $(303,85 \%)$, considerado ano habitual.

Como foi observado, a produção de milho e feijão diminuiu em alguns anos chuvosos, podendo haver relação entre a quantidade de chuva caída com a área onde são cultivados esses produtos, que são várzeas sujeitas a enchentes e em anos secos a produção pequena por causa do déficit hídrico. Com relação à baixa produção em alguns anos habituais, pode está relacionada com a má distribuição das chuvas. 
Tabela 07

\section{Produção da agricultura em Caicó/RN}

\begin{tabular}{|c|c|c|c|c|c|c|}
\hline \multirow[b]{3}{*}{ ANO } & \multicolumn{3}{|c|}{ Feijão (em grãos) } & \multicolumn{3}{|c|}{ Milho (em grãos) } \\
\hline & \multirow[b]{2}{*}{ TOTAL } & \multicolumn{2}{|l|}{ DESVIO } & \multirow[b]{2}{*}{ TOTAL } & \multicolumn{2}{|l|}{ DESVIO } \\
\hline & & (Toneladas) & $\%$ & & (Toneladas) & $\%$ \\
\hline 1996 & 228 & 140,00 & 159,09 & 271 & 187,80 & 225,72 \\
\hline 1997 & 36 & $-52,00$ & $-59,09$ & 10 & $-73,20$ & $-87,98$ \\
\hline 1998 & 13 & $-75,00$ & $-85,23$ & 4 & $-79,20$ & $-95,19$ \\
\hline 1999 & 0 & $-88,00$ & $-100,00$ & 0 & $-83,20$ & $-100,00$ \\
\hline 2000 & 180 & 92,00 & 104,55 & 240 & 156,80 & 188,46 \\
\hline 2001 & 6 & $-82,00$ & $-93,18$ & 0 & $-83,20$ & $-100,00$ \\
\hline 2002 & 295 & 207,00 & 235,23 & 336 & 252,80 & 303,85 \\
\hline 2003 & 57 & $-31,00$ & $-35,23$ & 19 & $-64,20$ & $-77,16$ \\
\hline 2004 & 28 & $-60,00$ & $-68,18$ & 8 & $-75,20$ & $-90,38$ \\
\hline 2005 & 108 & 20,00 & 22,73 & 30 & $-53,20$ & $-63,94$ \\
\hline 2006 & 92 & 4,00 & 4,55 & 70 & $-13,20$ & $-15,87$ \\
\hline 2007 & 72 & $-16,00$ & $-18,18$ & 32 & $-51,20$ & $-61,54$ \\
\hline 2008 & 173 & 85,00 & 96,59 & 160 & 76,80 & 92,31 \\
\hline 2009 & 7 & $-81,00$ & $-92,05$ & 8 & $-75,20$ & $-90,38$ \\
\hline 2010 & 25 & $-63,00$ & $-71,59$ & 60 & $-23,20$ & $-27,88$ \\
\hline$\overline{\bar{X}}$ & 88,00 & & & 83,20 & & \\
\hline $\mathbf{S}$ & 91,30 & & & 112,36 & & \\
\hline CV & 103,75 & & & 135,04 & & \\
\hline MÍN & 0 & & & 0 & & \\
\hline MÁX & 295 & & & 336 & & \\
\hline
\end{tabular}

Fonte: IBGE (2010). Org: Joselma Araújo de Lucena

Desse modo, o tratamento estatístico aplicado aos dados da pesquisa revela que os pequenos índices pluviométricos anuais são predominantes no quadro climático de Caicó/RN, embora apresente tendência de previsão linear positiva. De acordo com os fatos observados, a produção agrícola no ano mais chuvoso (2009) e nos anos mais secos (1998 e 1999) apresentou significativas perdas em relação à média. Neste sentido, a atividade agrícola está sujeita a eventos climáticos extremos. O planejamento deve estar voltado para o alerta junto aos órgãos competentes para as possibilidades de variações temporais muitas vezes inesperadas, as quais podem acarretar prejuízos econômicos para a população. As chuvas que regulam e suprem o ciclo hidrológico tem origem nas variações e desvios dos sistemas atmosféricos que atingem a região. Sendo assim, essas manifestações precisam ser analisadas para avaliar sua participação e importância no contexto climático da área de estudo. 


\section{CONSIDERAÇÕES FINAIS}

A agricultura se apresenta como um segmento importante na cadeia produtiva e depende em grande parte das condições naturais, principalmente do clima e do solo, pois estes vão controlar seu crescimento e desenvolvimento.-Nesse caso, quanto melhor o entendimento das condições ambientais de determinada região, mais apto se estará para a seleção das culturas mais adequadas e das melhores épocas de plantio, buscando uma melhor produção. Em casos de seca prolongada, com anos sucessivos de déficit pluviométrico e elevadas temperaturas, 0 sistema de produção de sequeiro fica bem mais dependente do meio ambiente e dos recursos naturais. Ao mesmo tempo, com chuvas concentradas e acima da média esperada, a produção também pode ser afetada, tendo em vista essa característica climática e a área onde são cultivados os gêneros agrícolas.

Considerando os resultados da pesquisa, percebe-se que, em condições adequadas, o clima e as variações climáticas exercem grande influência sobre a sociedade e suas atividades econômicas de modo positivo. Entretanto, em condições adversas manifestadas pela ocorrência de eventos extremos como enchentes, secas, entre outras, essa influência pode se dar de modo negativo, cuja intensidade pode variar de acordo com o nível socioeconômico das populações atingidas, particularmente na produção agrícola no semiárido nordestino, por ser praticada com baixos padrões tecnológicos.

Tendo em vista o período de análise feito neste trabalho, conclui-se que os meses chuvosos na área estudada se concentram de janeiro a maio, com distribuição irregular. Desse modo, se a maioria dos anos apresentaram desvios negativos na produção do milho e do feijão, podemos concluir que o município de Caicó representa um clima, cujas precipitações acumuladas tornam a localidade com dificuldades (em termos agronômicos) para o cultivo das culturas em função do grande risco de insucesso. Contudo, existe aparato tecnológico compatível com as condições ecológicas da região Nordeste do Brasil, embora a produção agrícola de sequeiro continue sujeita a violentas flutuações, desencadeadas por adversidades climáticas, demonstrando que um dos principais objetivos originais da política de desenvolvimento regional - fortalecer a economia da região semiárida contra os efeitos de eventos climáticos extremos - ainda está por ser exercido.

\section{REFERÊNCIAS}

.AB' SÁBER, Aziz Nacib. Os domínios de natureza no Brasil: potencialidades paisagísticas. São Paulo: Ateliê Editorial, 2003.

.ALMEIDA, M. D. L et al. A pegada ecológica do consumo de água do município de Caicó/RN. Holos, Ano 26, Vol. 5.

.ANTONINO, C. D. et al. Balanço hídrico em solo com cultivos de subsistência no semi-árido do Nordeste do Brasil. Campina Grande, PB, DEAg/UFPB. Revista Brasileira de Engenharia Agrícola e Ambiental, v. 4, n. 1, p. 29-34, 2000.

.AYOADE, J. O. Introdução a climatologia para os trópicos. Ed. 11a. - Rio de Janeiro: Bertrand Brasil, 2006.

.BALDO, M. C. et al. Análise da estrutura da precipitação pluviométrica na região sul do Brasil. Boletim de Geografia - Departamento de Geografia, UEM, Maringá, n. 1. 2001.

.BALDO, M. C. Variabilidade Pluviométrica e a dinâmica atmosférica na bacia hidrográfica do rio Ivaí - PR. (Tese de doutorado). Universidade Estadual Paulista. Presidente Prudente, 2006.

.BERGAMASCHI, H; MATZENAUER, R. Milho. In: Agrometeorologia dos Cultivos: o fator meteorológico na produção agrícola. MONTEIRO, José Eduardo B. A. (Org.). Brasília, DF: INMET, 2009.

.BRITO, Luzia Teixeira de Lima et al. Potencialidades da água de chuva no semi-árido brasileiro. Petrolina-PE: Embrapa Semi-Árido, 2007.

.HEINEMANN, A. B. et al. Feijão. In: Agrometeorologia dos Cultivos: o fator meteorológico na produção agrícola. MONTEIRO, José Eduardo B. A. (Org.). Brasília, DF: INMET, 2009.

.IBGE. Instituto Brasileiro de Geografia e Estatística. Disponível em: <www.ibge.gov.br>. Acesso 20.06.2011.

.KAYANO, M. T; ANDREOLI, R. V. Clima da região Nordeste do Brasil. In: CAVALCANTI, Iracema F. A. et al. Tempo e clima no Brasil. São Paulo: Oficina de textos, 2009. 
.MENDONÇA, F.; DANI-OLIVEIRA, I. M. Climatologia: noções básicas e climas do Brasil. Editora: oficina de textos, 2007.

.MONTEIRO, C. A. de F. Análise rítmica em climatologia - problemas da atualidade climática em São Paulo e achegas para um programa de trabalho. Climatologia 1, USP/IG, São Paulo, 1971.

.MORAES, B. C. et al. Variação espacial e temporal da precipitação no estado do Pará. Acta Amazonica. Vol. 35 (2), 2005.

.NUNES, L. H; LOMBARDO, M. A. A questão da variabilidade climática: uma reflexão crítica. Rev. IG. São Paulo, 16 (1/2), 1995.

.SANT'ANNA NETO, J. L. Ritmo climático e a gênese das chuvas na Zona Costeira Paulista. (Dissertação de Mestrado) - Faculdade de Filosofia, Letras e Ciências Humanas, Universidade de São Paulo, São Paulo. 168 p. 1990.

.SORRE, M. Lês fondements de la Géographie humaine. Paris: Armand Colin, 1951.

.SOUZA, C. F. de. Dinâmica climática e as chuvas no Nordeste brasileiro no eixo Barra do Corda/MA - Natal/RN (Relações com o fenômeno El Niño). (Tese de doutorado) USP, Departamento de Geografia. São Paulo, 1998.

.SOUZA, P. Estudo da variabilidade da precipitação no estado do Paraná associado à anomalia da TSM no Oceano Pacífico. Universidade Estadual de Maringá (Dissertação de Mestrado). Maringá, 2006. 